\title{
ICONOGRAFIA REVISITADA: UM PANORAMA TEMPORAL DE ÍCONES DA APPLE E DA MICROSOFT
}

Ana Carolina Cruz | Bolsista de Iniciação Científica CCPG/PUC-Rio

LEUI | Laboratório de Ergodesign e Usabilidade de Interfaces - PUC-Rio

anacarolina-f-c@hotmail.com

Patrícia Carrion | Mestranda Bolsista CAPES

LEUI | Laboratório de Ergodesign e Usabilidade de Interfaces - PUC-Rio

patriciac@aluno.puc-rio.br

Manuela Quaresma, D.Sc.

LEUI | Laboratório de Ergodesign e Usabilidade de Interfaces - PUC-Rio mquaresma@puc-rio.br

Resumo: Interfaces gráficas de dispositivos eletrônicos são compostas por um repertório de objetos visuais que têm como uma das suas principais funções facilitar a utilização por parte do usuário. No decorrer de quase meio século, tais objetos, em especial os ícones, sofreram grandes modificações. A princípio presentes em aparelhos como os computadores desktop, esses indicadores visuais migraram para as tecnologias mobile e, no contexto de telas menores, economizam espaço na interface e propõem uma interação de toque por parte do usuário. Tendo conhecimento sobre a importância destes recursos gráficos, esta pesquisa tem como objetivo mostrar a evolução dos ícones sob a perspectiva de duas populares plataformas, a Microsoft e a Apple, e seus respectivos software. Nos anos 80, o mundo foi apresentado ao primeiro computador pessoal comercial com uma interface gráfica do usuário (GUI). O lançamento do Lisa, da Apple, configurou-se, portanto, como um importante marco na história da computação, visto que dispositivos como o Microsoft Windows e o Apple Macintosh em breve adotariam as GUIs como suas interfaces de usuário. Nos anos 2000, com a popularização dos smartphones, indivíduos tiveram o acesso à tela na ponta dos dedos, e os aplicativos de dispositivos móveis inflamaram a criação de ícones gráficos. Nessa conjuntura, a Apple distinguiu-se, visto que, até a chegada do iOS, os smartphones não possuíam tela sensível ao toque. O iPhone original proporcionou uma mudança nesse cenário ao apresentar uma touchscreen capacitiva. Ao lançar o Windows Phone 7, a Microsoft também revolucionou, especialmente no que concerne aos ícones digitais, que se tornaram flat. De elementos visuais bem-sucedidos como os desenvolvidos pela designer Susan Kare a interfaces já descontinuadas como as do Microsoft Bob, apresenta-se neste estudo uma linha temporal de ícones de aplicações digitais. Em suma, busca-se auxiliar na compreensão e no estudo das 
tendências de design, como o skeumorfismo e suas metáforas visuais, o flat design e os desenhos 3D mais realistas.

Palavras-chave: Interação Humano-Computador, Interfaces Gráficas, Ícones, Apple, Microsoft. 